\title{
Major Histocompatibility Class II Molecules in the CNS: Increased Microglial Expression at the Onset of Narcolepsy in a Canine Model
}

\author{
Mehdi Tafti, ${ }^{1}$ Seiji Nishino, ${ }^{1}$ Michael S. Aldrich, ${ }^{2}$ Wennie Liao, ${ }^{1}$ William C. Dement, ${ }^{1}$ and Emmanuel Mignot ${ }^{1}$ \\ ${ }^{1}$ Sleep Disorders Center, Department of Psychiatry, Stanford University, Palo Alto, California 94304, and ${ }^{2}$ Department of \\ Neurology, University of Michigan, Ann Arbor, Michigan 48109
}

\begin{abstract}
Human narcolepsy is a neurological disorder known to be closely associated with HLA-DR2 and DQB1*0602. Because most autoimmune diseases are HLA-associated, a similar mechanism has been proposed for narcolepsy. However, neither systemic nor CNS evidence of an autoimmune abnormality has ever been reported. In this study, major histocompatibility (MHC) class I and class II expression was studied in the CNS of human and canine narcoleptics using immunohistochemistry and Northern analysis. Results indicate that canine narcolepsy is associated with a significant increase of MHC class II expression by the microglia. Moreover, the highest values were found between 3 and 8 months of age, strikingly concomitant to the development of narcolepsy in the canine model. In humans,
\end{abstract}

Human narcolepsy is a sleep disorder characterized by excessive daytime sleepiness and symptoms of abnormal rapid eye movement (REM) sleep such as cataplexy (attacks of muscle paralysis triggered by emotions) (Aldrich, 1990). Narcolepsy is also observed in animals, and the condition has been studied extensively in Doberman dogs, in which disease segregates as a single autosomal recessive trait with full penetrance (Baker and Dement, 1985; Mignot et al., 1991b).

The cause and pathogenesis of narcolepsy are still unclear but likely involve the immune system. Human narcolepsy is closely associated ( $>95 \%$ of cases) with the HLA class II alleles DQA1*0102 and DQB1*0602 (Matsuki et al., 1992; Mignot et al., 1994). In canines, narcolepsy cosegregates with a genomic fragment [outside the canine major histocompatibility (MHC)] with high homology with the human immunoglobulin $\mu$-switch segment (Mignot et al., 1991b). In spite of its association with immunerelated genes, narcolepsy does not seem to be a classical autoimmune disease (for review, see Mignot et al., 1995). Systemic measures of immune functions were found in the normal range even within a few months after disease onset (Matsuki et al., 1988). Similarly, no significant increase in classical autoantibodies or autoantibodies directed against neuroblastoma or glioblastoma cell lines could be found (Rubin et al., 1988). At the CNS level, minor abnormalities have been reported in the CSF of some narcoleptic subjects (Matsuki et al., 1988; Parkes et al., 1988; Fredrikson et al., 1990), but Fredrikson et al. (1990) did not find

Received March 11, 1996; revised April 29, 1996; accepted May 10, 1996.

This research was supported by NS/MH 33797 and NS 27710.

Correspondence should be addressed to Mehdi Tafti, Hôpitaux Universitaires de Genève, Neuropsychiatry Division, Chemin du Petit-Bel-Air, 2, 1225 Chêne-Bourg, Switzerland.

Copyright (C) 1996 Society for Neuroscience $0270-6474 / 96 / 164588-08 \$ 05.00 / 0$ class II expression was not found significantly different between control and narcoleptic subjects. This result could be explained by the old age of the subjects $(69.86 \pm 5.31$ and $68.36 \pm 4.74$ years in narcoleptics and controls, respectively), because class II expression is significantly correlated with age in both humans and dogs. For the first time, this study demonstrated that the expression of MHC class II molecules in the CNS is agedependent and that a consistent increase of their expression by the microglia might be critically involved in the development of narcolepsy.

Key words: narcolepsy; MHC class II; microglia; development; gene expression; immunohistochemistry; Northern analysis

increased IgG index or oligoclonal bands in the CSF of 15 human narcoleptics. These results suggest that if an autoimmune reaction is involved in narcolepsy, it is likely to be anatomically localized in the CNS and/or short-lasting.

The CNS has long been considered as an "immunologically privileged" site. The absence of lymphatic drainage and the presence of tight junctions in the blood-brain barrier are believed to prevent direct contact with the immune system. Moreover, $\mathrm{T}$ cell-mediated immune reactions seem to be prevented by the absence or the very low level of HLA expression in the brain (for review, see Wekerle et al., 1986). Most recent results, however, suggest that both immune and autoimmune-like responses can occur within the CNS. These processes mainly involve the microglia, a specialized population of CNS resident macrophages (Wekerle et al., 1986; Hickey and Kimura, 1988; Jordan and Thomas, 1988). Endothelial and perivascular cells constitutively express HLA class I molecules, and upregulated expression can be found in degenerative and/or inflammatory neurological disorders (Sobel et al., 1984; Lampson and Hickey, 1986; Sobel and Ames, 1988). Resting microglia may undergo rapid phenotypic changes ("activated microglia") with a marked increase in HLA class II expression that may be critical for antigen presentation (Hayes et al., 1987; Hickey and Kimura, 1988).

Reactive microglia with increased class II expression have been reported in a number of neurological disorders with direct or indirect immune involvement (for review, see McGeer et al., 1993). The microglia have also been found to be reactive in the CNS of various animal models of autoimmune diseases (Sobel et al., 1984; Matsumoto et al., 1986; Gehrmann et al., 1993b) and in normal animals after infection (Weinstein et al., 1990), injury (Gehrmann et al., 1991), or exposure to cytokines (Vass and Lassmann, 1990). Thus, in neurological disorders in which the 
existence of an immune etiology is controversial, analysis of MHC expression by the microglia in situ is highly informative. The aim of the present study was to explore this issue in narcolepsy through the study of class II expression in the brain of canine and human narcoleptic subjects.

\section{MATERIALS AND METHODS}

Canine tissue samples. Seventeen homozygous narcoleptic and 16 control Dobermans were included in the study. Narcoleptic dogs were from 13 different litters involving 8 sirs and 11 dams forming 9 related (parents with known common ancestor) and 4 unrelated (parents with no known common ancestor) litters. Control dogs were from 10 different litters involving 9 sirs and 8 dams forming 4 related and 6 unrelated litters. All dogs were housed at the Department of Animal Laboratory Medicine of the Stanford University and exposed to a 12:12 hr light/dark cycle with free access to food and water during the light period. All offspring born were housed with the mother for at least the first month after whelping. Litters were then split up, and animals were housed in individual cages $\left(100 \times 180 \mathrm{~cm}^{2}\right)$ after 4 months of age. All experiments were performed in accordance with the National Institutes of Health Guide for Care and Use of Laboratory Animals.

Both fresh frozen and fixed tissues were used in the present study. For fresh frozen samples (13 narcoleptics and 12 controls), animals were killed and brains were quickly removed and frozen in dry ice-cooled isopentane. Selected blocks were cut at $30 \mu \mathrm{m}$ in a freezing cryostat $\left(-20^{\circ} \mathrm{C}\right)$, and the sections were directly mounted onto gelatin-coated slides. All slides were air-dried for $30 \mathrm{~min}$ and stored at $-20^{\circ} \mathrm{C}$ until used. For fixed samples (4 narcoleptics and 4 controls), animals were deeply anesthetized $(50 \mathrm{mg} / \mathrm{kg}$ pentobarbital) and perfused via the ascending aorta (4 1 of saline with $2000 \mathrm{U} / 1$ heparin followed by 41 of ice-cooled $4 \%$ paraformaldehyde in $0.1 \mathrm{M}$ PBS, $\mathrm{pH}$ 7.4). Brains were then removed (first $4-5 \mathrm{~cm}$ of spinal cord included), post-fixed in paraformaldehyde solution for $6 \mathrm{hr}$, dissected into $1-1.5 \mathrm{~cm}$ blocks, and cryoprotected in $30 \%$ sucrose, $0.1 \mathrm{M}$ PBS, $0.1 \%$ sodium azide at $4^{\circ} \mathrm{C}$ for $3-5 \mathrm{~d}$. Blocks were frozen in liquid $\mathrm{CO}_{2}$ and cut at $30 \mu \mathrm{m}$ in a freezing cryostat at $-24^{\circ} \mathrm{C}$. Nine series of sections were prepared: three series directly mounted onto gelatin-coated slides and kept at $-20^{\circ} \mathrm{C}$ and six free-floating series kept in $0.1 \mathrm{M}$ PBS after three $30 \mathrm{~min}$ rinses; these were stored at $4^{\circ} \mathrm{C}$ in $0.1 \mathrm{M}$ PBS with $0.1 \%$ sodium azide.

Human tissue samples. Seven narcoleptic (all with cataplexy; 6 men and 1 woman; mean age $69.86 \pm 5.31$ years) and 14 control subjects ( 9 men and 5 women; mean age $68.36 \pm 4.74$ years) were studied (for clinical descriptions, see Aldrich et al., 1994). All subjects were HLA typed using brain-extracted DNA (at the Stanford Blood Bank). All narcoleptic subjects were found to be DR2-positive and/or DQB1*0602-positive. Three control subjects were found to be also DR2- and/or DQB1*0602positive, and in one subject the HLA status could not be determined (absence of gene amplification). Tissue samples included blocks prepared from frontal cortex (5 narcoleptics and 11 controls), rostral pons (3 narcoleptics and 2 controls), and midpontine level (1 narcoleptic and 1 control), prepared as described in Aldrich et al. (1994). Briefly, brain tissue was removed shortly after death (mean postmortem delay before freezing was $19.61 \pm 8.21 \mathrm{hr}$ for the narcoleptic subjects and $16.36 \pm 1.42$ $\mathrm{hr}$ for the control subjects), cut into $1 \mathrm{~cm}$ slices, frozen in crushed dry ice, and stored at $-70^{\circ} \mathrm{C}$. Selected tissue blocks were then warmed to $-20^{\circ} \mathrm{C}$, and $20 \mu \mathrm{m}$ sections were cut in a freezing cryostat. Sections were directly thaw-mounted onto gelatin-coated slides, air-dried for $30 \mathrm{~min}$, and stored at $-20^{\circ} \mathrm{C}$ until used.

Antibody characterization. The following primary antibodies were used: anti-human $\beta-2$ microglobulin (Dako, Carpenteria, CA), W6/32 (antihuman MHC class I, Dako), TAL. 1B5 (anti-human DR- $\alpha$, Dako, CA), CR3/43 (anti-human MHC class II, Dako), CD45 (anti-leukocyte common antigen, Dako), anti-human C3bi-receptor (CD18, Dako), antihuman leukocyte function associated-1 $\beta$-chain (CD11, Dako), antihuman HLA-DR (Becton Dickinson, Mountain View, CA), anti-Leu-10 (anti-human HLA-DQ, Becton Dickinson), H58A (cross-reactive anticanine class I, VMRD), CA2.1C12 (anti-canine class II; generous gift from Dr. P. F. Moore, University of California at Davis, Davis CA), AcM1 (anti-canine-activated T cells), and 2B3 (anti-canine-activated monocytes, both generous gifts from Dr. D. Rigal, University of Lyon, Lyon, France). All antibodies were tested in both human and canine brain and lymphoid tissue samples (tonsils, thymus, and lymph nodes) to determine cross-species reactivity. Only one class II human monoclonal antibody (TAL. 1B5) cross-reacted strongly with the corresponding ca- nine antigen. Monoclonal antibody CR3/43 (another anti-human class II) gave some faint cross reactivity in a few dogs but was clearly inferior to TAL. 1B5. The mouse anti-human TAL. 1B5 (DR- $\alpha)$ that gave the best results in both human and canine tissues was further used on immunoblots loaded with protein extracts from canine peripheral lymphocytes, and human and canine white and gray matter. In all samples analyzed, a single band of the expected molecular weight for HLA-DR $(\sim 34 \mathrm{kDa})$ was observed, and control membranes processed without the primary antibody were uniformly blank. This led us to select the TAL. 1B5 antibody for all further studies. An anti-canine class II antibody CA2.1C12 was also tested midway through these studies, and its reactivity in terms of specificity and staining intensity was found to be identical to TAL. 1B5. All the results reported in this work for class II immunoreactivity were therefore generated using TAL. 1B5.

Immunohistochemical studies. Sections were fixed in $4 \%$ paraformaldehyde for $10-30 \mathrm{~min}$, placed in a blocking solution (10\% normal horse serum, $0.1 \%$ bovine serum albumin in $0.1 \mathrm{M}$ PBS for $60 \mathrm{~min}$ ), and incubated overnight at $4^{\circ} \mathrm{C}$ with the corresponding primary antibody (1:100 dilution). This was followed by PBS rinses, an incubation with the biotinylated secondary antibody (horse anti-mouse IgG, Vector Laboratories, Burlingame, CA) for $90 \mathrm{~min}$ at room temperature, a $30 \mathrm{~min}$ rinsing, and a 90 min incubation with an avidin-biotin-peroxidase complex (ABC kit, Vector) at room temperature. The reaction product was developed with $0.02 \%$ 3,3'-diaminobenzidine tetrahydrochloride (Sigma, St. Louis, MO), $0.003 \% \mathrm{H}_{2} \mathrm{O}_{2}$ in $0.05 \mathrm{M}$ Tris- $\mathrm{HCl}, \mathrm{pH}$ 7.6. Positive control sections for HLA staining included tissues from one narcoleptic canine's tonsil and one narcoleptic puppy's thymus, whereas negative control sections were brain tissues incubated either without the primary or secondary antibody or with an irrelevant secondary antibody (anti-rabbit IgG instead of anti-horse $\operatorname{IgG}$ ).

Fixed tissue sections were used for glial fibrillary acidic protein (GFAP; astrocyte marker, Dako) and nucleoside diphosphatase (NDPase; microglial marker) staining. NDPase activity was demonstrated according to Murabe and Sano (1982) with modification for slide-mounted sections. Briefly, fixed sections were rehydrated in $0.2 \mathrm{~m}$ Tris-maleate buffer, $\mathrm{pH}$ 7.2 , and incubated in the same buffer containing $8 \%$ sucrose overnight at $4^{\circ} \mathrm{C}$. Sections were then incubated in $4 \mathrm{ml}$ of $0.2 \mathrm{M}$ Tris-maleate buffer, $\mathrm{pH}$ $7.2,1.2 \mathrm{ml}$ of $1 \%$ lead nitrate, $2 \mathrm{ml}$ of $0.5 \%$ manganese chloride, $0.1 \mathrm{ml}$ of dimethylsulfoxide, $1.35 \mathrm{ml}$ of distilled water, and $1 \mathrm{ml}$ of $10 \mathrm{~mm}$ inosine diphosphate at $37^{\circ} \mathrm{C}$ for $30 \mathrm{~min}$. Sections were then rinsed in distilled water and immersed in $2 \%$ aqueous ammonium sulfide solution for $2 \mathrm{~min}$.

Analysis of proteins by immunoblots (Western analysis). Integral membrane proteins were extracted from peripheral lymphocytes and fresh frozen brain tissues with $1 \%$ Triton X-114 in Tris-buffered saline $(0.9 \%$ $\mathrm{NaCl}, 20 \mathrm{~mm}$ Tris, $\mathrm{pH}$ 7.4) according to Bordier (1981). Protein samples were separated by sodium dodecyl sulfate-polyacrylamide gel electrophoresis and electrophoretically transferred to nitrocellulose membranes. After blocking with 5\% nonfat dry milk in $0.1 \mathrm{M}$ PBS, membranes were processed as the tissue sections for immunohistochemistry.

Analysis of RNAs by blot hybridization (Northern analysis). Total RNA was extracted from subcortical white and adjacent gray matter in eight narcoleptic and eight control dogs using a monophasic solution of phenol and guanidine isothiocyanate (TRIzol Reagent, Gibco, Gaithersburg, MD). Samples were taken from the same tissue blocks where sections had been cut for immunohistochemical studies (at the level of the anterior commissure: gray matter: motor cortex; white matter: immediately under the motor cortex). RNA samples ( $35 \mu \mathrm{g}$ ) were subjected to denaturing electrophoresis in $1.2 \%$ agarose gel for $16 \mathrm{hr}$, transferred onto nylon filters (Schleicher \& Schuell, Keene, NH) in $20 \times$ SSC for $20 \mathrm{hr}$, and UV cross-linked. Full-length cDNA of DQB1*0602 from a narcoleptic human subject and of DQA $1 * 0101$ from a narcoleptic dog were prepared by RT-PCR, cloned in pT7Blue (Novagen, Madison, WI) followed by plasmid isolation. Filters were subsequently hybridized with ${ }^{32} \mathrm{P}$-labeled cDNAs to detect the relative amount of class II mRNA, and with a human $\beta$-actin and a human $\beta$-tubulin to control for variability in loading and transfer. Relative optical densities of Northern autoradiograms were calculated (MCID; Imaging Research, St. Catharine's, Ontario) using the ratio of optical densities of class II probes over those of control probes.

\section{RESULTS}

\section{Canine narcolepsy is not associated with a localized inflammatory process}

In our first series of experiments, the entire brain and spinal cord of four narcoleptic and four control dogs (adult dogs, fixed tissue) 
were screened using routine histological methods and HLA-DR immunohistochemistry. No overt localized inflammation, lymphocyte infiltration, or massive cellular degeneration was observed (Tafti et al., 1994), but the resting microglia were found to be weakly HLA-DR-reactive in both control and narcoleptic animals. Activated $\mathrm{T}$ cells or monocytes immunoreactive with AcM1 and 2B3 antibodies were not observed. We then hypothesized that an immunological reaction may have occurred before or at the onset of narcolepsy and could have disappeared by adulthood. We therefore studied HLA-DR expression in the brain of three young narcoleptic dogs (3-week- and 1-month-old homozygous narcoleptic puppies before the disease onset, and a 3-month-old homozygous narcoleptic dog at narcolepsy onset). The 3-month-old narcoleptic animal had been killed 3 d after cataplectic attacks were first observed. The entire three brains were analyzed, and no major localized immunological reaction was found. However, sections from the 3-month-old dog strongly stained for HLA-DR when compared with the two younger puppies (Fig. 1a,b). The staining was confined to the microglia with much higher density in the white matter (diffuse staining without any specific localization), thus prompting us to compare the HLA class II expression in narcoleptic and control animals at various ages.

\section{MHC class I and II immunoreactivity in the dog}

Fresh frozen brain tissue from our Canine Brain Bank (19891995) was used for these experiments. Sections were generated at the level of anterior commissure (AC) (corresponding to R25 according to the stereotaxic atlas of the dog's brain) (Lim et al., 1960) and in a few dogs through the spinal cord. The AC was used as an anatomical landmark to be able to generate sections at the same level in all dogs (the $\mathrm{AC}$ is $<1 \mathrm{~mm}$ thick in the dog) and to have a large area containing substantial amount of white and gray matter for RNA and protein extraction. Eleven narcoleptic and 11 control dogs, from 3 months to 4 years, were included in the study. For all the comparison studies, all sections were processed in parallel.

Class I immunoreactivity was found to be associated with small blood vessels and resting microglia (Fig. $1 d$ ) and did not show any difference between narcoleptic and control dogs.

In most sections, resting microglia and in some cases perivascular cells were also HLA-DR-positive. Although the white matter was more strongly stained, staining was also occasionally observed in the gray matter, for instance at the level of the globus pallidus. In addition, reactive microglia and aggregated materials, immunoreactive with DR antibody, were frequently observed in the white matter of narcoleptic dogs (Fig. 1b).

The identity of the cells expressing MHC class II antigens was verified using GFAP and NDPase staining. Figure $1, e$ and $f$, shows two sections in a narcoleptic dog stained for GFAP and NDPase. HLA-DR- $\alpha$-immunoreactive cells (Fig. $1 b$ ) present a morphology typical of microglia as revealed with NDPase and distinct from that of astrocytes stained with GFAP.

For further comparisons, all sections were coded and analyzed blindly by two independent investigators (S.N. and E.M.) for the intensity and the extent of staining (scored from 0 to 10 , where 0 $=$ absence of staining and $10=$ highest staining). Two sections per dog were included, and all sections were scored twice by the two raters. Mean scores were analyzed using ANOVA with factors group and age (the youngest puppies were not included in this analysis because narcoleptic canines were still asymptomatic at this age). Age-matched narcoleptic sections were rated significantly higher than control sections $(5.02 \pm 0.30$ vs $3.50 \pm 0.31$; overall grouping factor $F_{(1,80)}=11.08 ; p<10^{-3}$; ANOVA) with a very high inter-scorer reliability $\left(r_{\mathrm{s}}=0.74 ; p<10^{-3}\right)$. The increased immunoreactivity could also be verified by Western blot analysis, with narcoleptic animals displaying a more intense HLA-DR $34 \mathrm{kDa}$ immunoreactive band (data not shown).

The immunoreactivity was age-dependent in both groups (overall aging factor $F_{(3,80)}=17.01 ; p<10^{-3}$; no interaction between age and group; ANOVA). Low staining on round (ameboid-like) microglia was apparent at 3 weeks and 1 month of age, whereas a sudden increase to a high level was observed at approximately 3 months of age (Fig. $2 A$ ), with narcoleptics displaying significantly higher values at early ages ( 3 and 8 months; $p<0.01$; post hoc Scheffe's test). The highest scores were obtained at 3 months of age followed by a sharp decrease at 8 months and a progressive increase thereafter. Note that the sharp increase in class II expression is concomitant to the development of cataplexy in our Doberman colony (Fig. 2B)

\section{HLA class I and II immunoreactivity in human tissue samples}

Antibodies to HLA-ABC and $\beta-2$ microglobulin strongly stained human samples. Staining was predominant at the level of small blood vessels (endothelial cells), but microglial cells were also class I-immunoreactive (Fig. $1 j$ ).

A procedure of blind scoring and comparison, similar to that described for the canine study, was also applied for the analysis of class II expression in humans. When present, the staining was confined to the white matter with both microglia and perivascular cells immunoreactive (Fig. 1g,h). The highest level of expression and the most frequent detection of class II immunoreactivity were in the pons of older subjects (Fig. 1i). In these subjects, a greater number of ramified and activated microglia, aggregated material, and perivascular cells were strongly class II-positive. The mean scores did not differ between groups $(3.62 \pm 0.34$ vs $3.47 \pm 0.24$ for the narcoleptic and the control group, respectively) and were not dependent on the DR2/DQB1*0602 status of the subjects. However, as in the adult dogs, the level of staining showed a progressive increase with age. This pattern led to a significant correlation between the HLA class II expression and age $\left(r_{\mathrm{s}}=\right.$ $0.44 ; p<0.05)$.

\section{Northern analysis of class II expression in the dog}

To further quantify and compare the class II gene expression in the CNS, total RNA samples extracted from eight narcoleptic and eight control canine subjects (aged 3-8 months) were hybridized with two class II cDNA probes (human DQB1 and canine DQA1). Samples included cortical white and gray matter for each individual. Using two different reference standards ( $\beta$-actin and $\beta$-tubulin) as probes, the relative amount of these class II mRNAs was found to be significantly increased in narcoleptic dogs when compared with controls (Table 1 ; overall $F_{(1,96)}=12.11 ; p<$ $10^{-3}$; ANOVA). Post hoc comparisons indicated that the difference was mainly attributable to a significant increase of class II expression in the white matter of narcoleptic dogs (Table 1; Student's $t$ tests), thus confirming our immunocytochemical finding.

\section{DISCUSSION}

The careful analysis of the entire brain of four adult and three young (before and at the onset of disease) narcoleptic dogs, using both classical neurohistology and HLA-DR staining, did not reveal any sign of localized inflammation or lymphocyte infiltration. The explored regions included the pontine reticular formation 


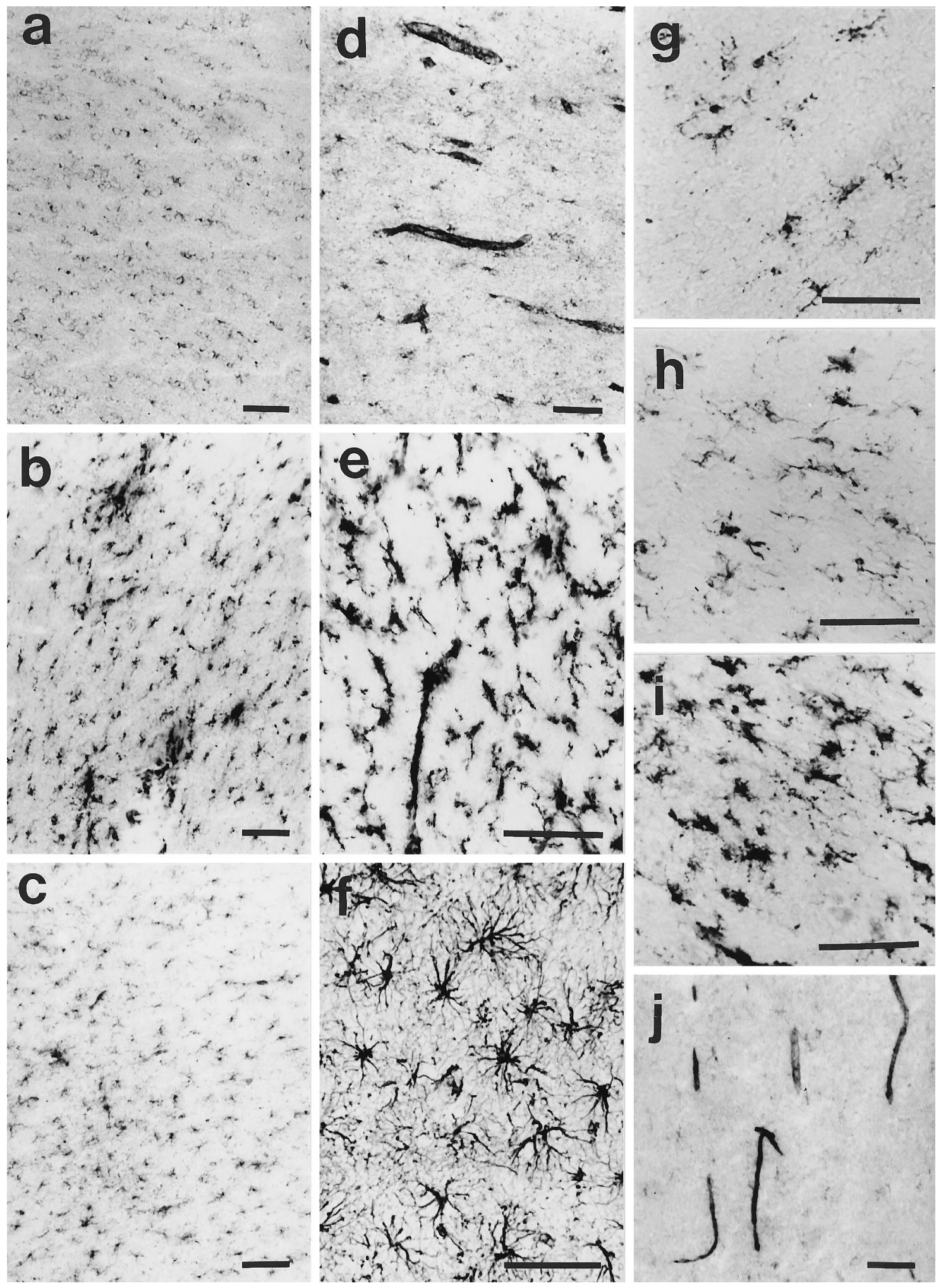

Figure 1. a, HLA-DR expression in a 3-week-old narcoleptic puppy. $b$, c , HLA-DR expression in a 3-month-old narcoleptic and a 3-month-old control dog. $d$, Class I expression in a narcoleptic dog. $e$, NDPase staining of microglia. $f$, GFAP staining of astrocytes. All sections $(a-f)$ were cut at the level of the anterior commissure, and figures show a portion of the white matter immediately under the motor cortex. $g$, $h$, HLA-DR expression in the cortical white matter of a 76-year-old human control and a 77-year-old human narcoleptic subject. $i$, HLA-DR expression in the pons of a human narcoleptic subject. $j$, Class I expression in the cortical white matter of a human narcoleptic subject. Scale bars, $100 \mu \mathrm{m}$. 
Figure 2. Class II expression in dogs as a function of age. $A, \mathrm{~A}$ transient increase is observed at 3 months followed by a sharp decrease at 8 months and a progressive increase thereafter, with narcoleptics displaying significantly higher values at early ages (3-8 months). One dog in each group at the 3 month point was 4 months old and one narcoleptic dog at the 8 month point was 7 months old. All other older dogs were killed at the indicated age \pm 1 month. Mean scores ( \pm SEM) are based on a semiquantitative analysis of the immunoreactivity to an HLA-DR antibody (TAL. 1B5). ANOVA indicated that both grouping (narcoleptic vs control; $F_{(1,80)}=11.08 ; p<$ $10^{-3}$ ) and aging (from 3 to 48 months; $F_{(3,80)}=17.00 ; p<10^{-3}$ ) factors were highly significant, although there was no significant interaction between factors $\left(F_{(3,80)}=0.51 ; p=0.68\right)$. The youngest puppies ( $<3$ months old) were not included in the statistical analysis because homozygous narcoleptic animals are still asymptomatic at these ages. ${ }^{*} p<0.01$; post hoc Scheffe's test comparisons between the two groups. $B$ replicates the typical evolution of cataplexy with age in our Doberman colony (Mignot et al., 1991a). Data represent the mean \pm SEM of 25 narcoleptic dogs. Note that the increase of class II expression is concomitant to the development of cataplectic attacks in the Doberman (between 1 and 5 months). (An animal is considered narcoleptic as soon as spontaneous and/or food-elicited cataplectic attacks are observed.)
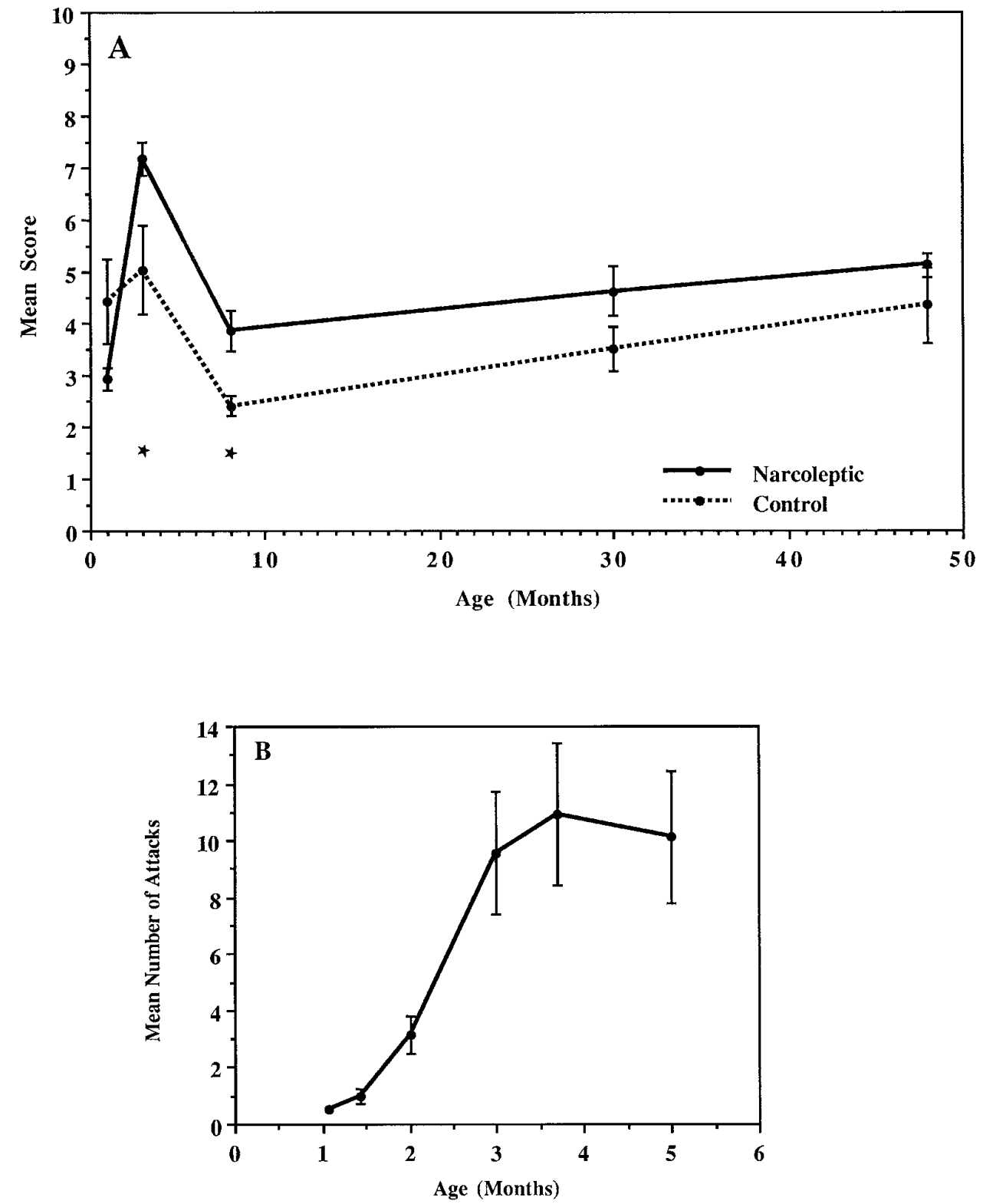

and other regions of the pontine brainstem that are known to be critical to the generation of REM sleep as well as the basal forebrain area and the amygdala, two regions of the forebrain that have been involved in the pathophysiology of narcolepsy through neurochemical and neurophysiological studies (Reid et al., 1994; Nishino et al., 1995). This result, rather, argues against a localized, short-lasting autoimmune process in narcoleptic canines. Although histopathological studies in human narcolepsy have reported some localized abnormalities in individual brain specimens (Erlich and Itabashi, 1986; Leverenz et al., 1988; Aldrich and Naylor, 1989; Kish et al., 1992), no consistent pattern has yet emerged. The lack of significant modification in the peripheral and central immunological parameters (Matsuki et al., 1988; Rubin et al., 1988; Fredrikson et al., 1990; Tafti et al., 1994) is also in good agreement with the present data, suggesting that with the techniques used so far, there is no evidence of an autoimmune process causing anatomical damage to the CNS in narcolepsy.

In contrast to this lack of localized immunopathology, a diffuse increase in microglial MHC class II expression was observed, predominantly in the white matter of narcoleptic dogs. This was evidenced at the cellular and molecular level using DR- $\alpha$ immunohistochemistry and DQA and DQB Northern analysis, respectively (Fig. 1, Table 1). This phenomenon could be secondary to an as yet unknown neuroanatomically generalized autoimmune or degenerative process. Increased HLA expression, together with reactive microglia, has been reported in natural or experimental autoimmune disorders such as multiple sclerosis (Woodroofe et al., 1986) and experimental autoimmune encephalitis (EAE), in degenerative disorders such as Alzheimer's disease and other neurological disorders (McGeer et al., 1988, 1993; Haga et al., 1989; Mattiace et al., 1990; Perlmutter et al., 1990; Kawamata et al., 1992), or as a result of deafferentation (Gehrmann et al., 1991). Arguing against this hypothesis, however, is the fact that the increased HLA expression observed in this study was not associated with any other obvious neuropathological abnormalities.

One of the most important findings in this study is the positive relation between HLA expression and age. The highest level of 
Table 1. DQA $(n=8)$ amd DQB $(n=6)$ mRNA expression was quantified using relative optical densities (ROD) on Northern autoradiograms

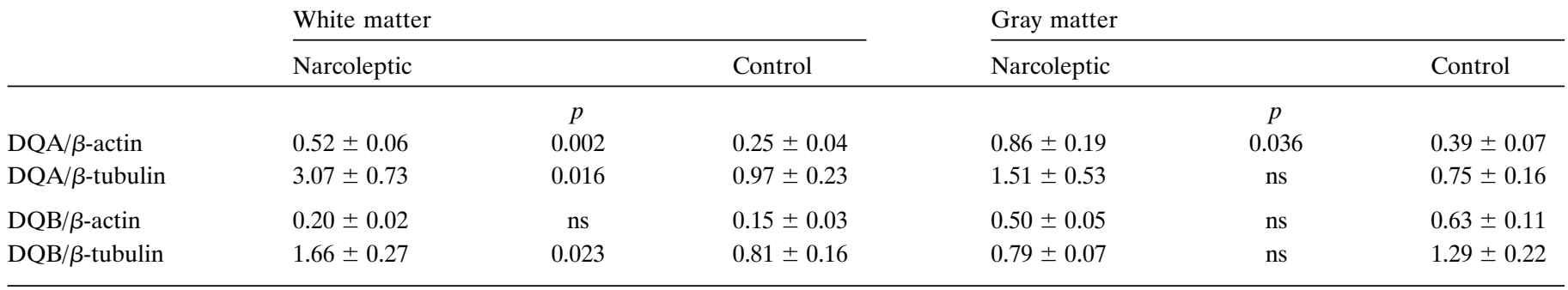

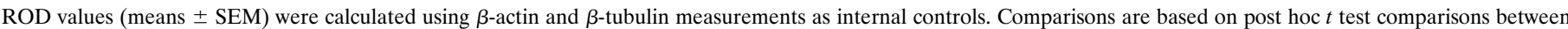
the narcoleptic and the control group. ns, Not significant.

expression was found at approximately 3 months of age in both narcoleptic and control dogs. This period strikingly coincides with the development of narcolepsy in the Doberman (the large majority of animals becoming symptomatic between 1 and 6 months of age; Fig. $2 B$ ). We therefore hypothesize that there might be a time period corresponding to the final developmental stages of the microglia in the canine species in which an increase in HLA class II can trigger the disease in genetically predisposed animals. Indeed, even if the microglia origin is still uncertain, its ramified fully differentiated form appears only postnatally in rodents (2 weeks in rats) (Ling et al., 1991). Its most probable precursor is the ameboid microglia, a rounded form of the cell that appears antenatally and disappears approximately 2 weeks after birth in rats (Ling et al., 1991). Ameboid microglia have been shown to express MHC class I but not class II molecules in rats (Ling et al., 1991). Our finding that 1-month-old canine brains have a low class II expression is thus compatible with the presence of ameboid microglia at this developmental stage in canines. A transitory increased class II activation would then occur when the microglia are finally setting in as ramified, fully differentiated cells at approximately 3 months of age (Fig. $1 b$ ).

In adult humans and dogs, a progressive age-dependent increase in class II expression was also found in both narcoleptic and control subjects. This finding is consistent with previously reported data in humans (McGeer et al., 1988; Rogers et al., 1988; Sobel and Ames, 1988; Mattiace et al., 1990; Styren et al., 1990) and rats (Perry et al., 1993). It is believed to reflect an increased CNS tissue damage with aging (Perry et al., 1993). In our study, the age-dependent increase was evident in both normal and narcoleptic adult dogs (Fig. $2 A$ ) and led to the disappearance of any significant difference between groups at 18 months of age. In humans, all of our subjects were adults (mean age $69.86 \pm 5.31$ years in narcoleptics and $68.36 \pm 4.74$ years in controls), and most of them were older than 70 years. We thus believe that the lack of significant difference in humans might be attributable to the confounding effect of age on HLA expression.

Although the role of activated microglia as a first line of defense against damage or infection in the CNS is well established, the existence and the role of class II molecules on normal ramified microglia has long been a controversial issue. Most, but not all authors, believe that ramified microglia constitutively express MHC molecules in adult human and animal tissue (Esiri and McGee, 1986; Hayes et al., 1987; Cuzner et al., 1988; Luber-Narod and Rogers, 1988; Vass and Lassmann, 1990; Gehrmann et al., 1991, 1993a; Graeber et al., 1992; Sasaki and Nakazato, 1992; Sedgwick et al., 1993). The amount of class II expression depends on the genetic background with specific rodent strains displaying much higher levels of expres- sion, a phenomenon that may correlate with resistance to the induction of EAE in Brown Norway rats (Sedgwick et al., 1993). Finally, expression in normal tissue is found mainly in the white matter, whereas microglia are more abundant in the gray matter, with the hippocampus, the globus pallidus, and the substantia nigra presenting the highest values (Lawson et al., 1990). This specialized distribution has not yet received any explanation. In our canine study, we found that the globus pallidus displayed rare immunoreactive microglia, whereas the substantia nigra was never MHC class II-positive in spite of its high density in microglia. Thus, the pattern of MHC expression is obviously not related to the relative abundance of microglia; more likely it is related to some functional role of microglia in the brain. One possibility might be that normal ramified microglia are involved in the specialized and selected presentation of CNS-specific antigens to the peripheral immune system independently of any pathological process. This function could have a specific importance at precise developmental time points and neuroanatomical locations (e.g., 3 months), possibly for the development of tolerance to selected CNS antigens. In this context, narcolepsy could represent a specialized type of CNS-autoimmune disorder.

The upregulated expression of MHC molecules without any noticeable inflammation might have some completely different and as yet unraveled function in the CNS. Microglia may first influence sleep directly via the release of specific immune factors. When activated, microglia secrete interleukins-1, -3, and -6 (Giulian et al., 1986; Frei et al., 1989; Ganter et al., 1992), macrophage-colony stimulating factor (Raivich et al., 1994), and tumor necrosis factor (Frei et al., 1987; Sawada et al., 1989). Recent studies have shown that cytokines have strong sleep-inducing effects (Krueger et al., 1984, 1990; Kapas et al., 1992). In addition, the cultured microglia are induced by lipopolysaccharide or cytokines to synthesize nitric oxide (Colton and Gilbert, 1987; Boje and Arora, 1992), which acts as a neurotoxin but also as a sleep-regulating factor (Kapas et al., 1994a,b). This suggests that activated microglia may directly be responsible for sleepiness in narcolepsy. Nonimmune functions of microglia with indirect trophic effects may also be involved. The microglia, for example, are known to secrete nerve growth factor (Mallat et al., 1989) and plasminogen (Nakajima et al., 1992). Plasminogen is neurotrophic for rat mesencephalic dopaminergic neurons in vitro and increases dopamine uptake and the number of tyrosine-hydroxylase-expressing neurons (Nakajima et al., 1994). Complex microglial-neural interactions during development also might be involved in the pathophysiology of narcolepsy.

Finally, the possibility that the inbreeding could explain the 
increased class II expression cannot be completely ruled out at this point. Our narcoleptic colony is partially inbred, and both narcoleptic and control dogs used in this study came from a relatively small number of litters (13 and 10 litters, respectively). The fact that our canine narcoleptic colony is regularly outbred by backcrossing and includes unrelated animals diagnosed all over the country makes this hypothesis unlikely, although impossible to exclude at the present time. We are now setting up narcoleptic $\times$ heterozygous and heterozygous $\times$ control backcrosses to study the MHC expression in related animals within single litters to confirm our finding.

\section{REFERENCES}

Aldrich MS (1990) Narcolepsy. N Engl J Med 323:388-394.

Aldrich MS, Naylor MW (1989) Narcolepsy associated with lesions of the diencephalon. Neurology 39:1505-1508.

Aldrich MS, Prokopowicz G, Ockert K, Hollingsworth Z, Penney JB, Albin RL (1994) Neurochemical studies of human narcolepsy: alphaadrenergic receptor autoradiography of human narcoleptic brain and brainstem. Sleep 17:598-608.

Baker TL, Dement WC (1985) Canine narcolepsy-cataplexy syndrome: evidence for an inherited monoaminergic-cholinergic imbalance. In: Brain mechanisms of sleep (McGinty DJ, Drucker-Colin R, Morrison A, Parmengiani P, eds), pp 199-233. New York: Raven.

Boje KM, Arora PK (1992) Microglial-produced nitric oxide and reactive nitrogen oxides mediate neuronal cell death. Brain Res 587:250-256.

Bordier C (1981) Phase separation of integral membrane proteins in Triton X-114 solution. J Biol Chem 256:1604-1607.

Colton CA, Gilbert DL (1987) Production of superoxide anions by a CNS macrophage, the microglia. FEBS Lett 223:284-288.

Cuzner ML, Hayes GM, Newcomb J, Woodroofe MN (1988) The nature of inflammatory components during demyelination in multiple sclerosis. J Neuroimmunol 20:203-209.

Erlich S, Itabashi H (1986) Narcolepsy: a neuropathological study. Sleep 9:126-132.

Esiri MM, McGee J (1986) Monoclonal antibody to macrophages (EBM/ 11) labels macrophages and microglial cells in human brain. J Clin Pathol 39:615-621.

Fredrikson S, Carlander B, Billiard M, Link H (1990) CSF immune variable in patients with narcolepsy. Acta Neurol Scand 81:253-254.

Frei K, Siepl C, Groscurth P, Bodmer S, Schwerdel C, Fontana A (1987) Antigen presentation and tumor cytotoxicity by interferon-gamma treated microglial cells. Eur J Immunol 17:1271-1278.

Frei K, Malipiero UV, Leist TP, Zinkernagel RM, Schwab ME, Fontana A (1989) On the cellular source and function of interleukin 6 produced in the CNS in viral diseases. Eur J Immunol 19:689-694.

Ganter S, Northoff H, Mennel D, Gebicke-Haerter PJ (1992) Growth control of cultured microglia. J Neurosci Res 33:218-230.

Gehrmann J, Monaco S, Kreutzberg GW (1991) Spinal cord microglial cells and DRG satellite cells rapidly respond to transection of the rat sciatic nerve. Restor Neurol Neurosci 2:181-198.

Gehrmann J, Banati RB, Kreutzberg GW (1993a) Microglia in the immune surveillance of the brain: human microglia constitutively express HLA-DR molecules. J Neuroimmunol 48:189-198.

Gehrmann J, Gold R, Linington C, Lannes-Vieira J, Wekerle H, Kreutzberg G (1993b) Microglial involvement in experimental autoimmune inflammation of the peripheral and central nervous system. Glia 7:50-59.

Giulian D, Baker TJ, Shin L, Lachman LB (1986) Interleukin 1 of the CNS is produced by ameboid microglia. J Exp Med 164:594-604.

Graeber MB, Streit WJ, Buringer D, Sparks L, Kreutzberg GW (1992) Ultrastructural location of major histocompatibility complex (MHC) class II positive perivascular cells in histologically normal human brain. J Neuropathol Exp Neurol 51:303-311.

Haga S, Akai K, Ishii T (1989) Demonstration of microglial cells in and around senile (neuritic) plaques in the Alzheimer brain. An immunohistochemical study using novel monoclonal antibody. Acta Neuropathol (Berl) 77:569-575.

Hayes GM, Woodroofe MN, Cuzner ML (1987) Microglia are the major cell type expressing MHC class II in human white matter. J Neurol Sci 80:25-37.
Hickey WF, Kimura H (1988) Perivascular microglial cells of the CNS are bone marrow-derived and present antigen in vivo. Science 239:290-292.

Jordan FL, Thomas WW (1988) Brain macrophages: question of origin and interrelationships. Brain Res Rev 13:165-178.

Kapas L, Hong L, Cady AB, Opp MR, Postlethwaite AE, Seyer JM, Krueger JM (1992) Somnogenic, pyrogenic, and anorectic activities of tumor necrosis factor-alpha and TNF-alpha fragments. Am J Physiol 263:R708-R715.

Kapas L, Fang J, Krueger JM (1994a) Inhibition of nitric oxide synthesis inhibits rat sleep. Brain Res 664:189-196.

Kapas L, Shibata M, Kimura M, Krueger JM (1994b) Inhibition of nitric oxide synthesis suppresses sleep in rabbits. Am J Physiol 266:R151-R157.

Kawamata T, Akiyama H, Yamada T, McGeer PL (1992) Immunologic reactions in amyotrophic lateral sclerosis brain and spinal cord tissue. Am J Pathol 140:691-707.

Kish SJ, Mamelak M, Slimovitch C, Dixon LM, Lewis A, Shannak K, Distephano L, Chang LJ, Hornykiewitz O (1992) Brain neurotransmitter changes in human narcolepsy. Neurology 42:229-234.

Krueger JM, Walter J, Dinarello CA, Wolff SM, Chedid L (1984) Sleeppromoting effects of endogenous pyrogen (interleukin-1). Am J Physiol 246:R994-R999.

Krueger JM, Obal F, Opp M, Toth L, Johannsen L, Cady AB (1990) Somnogenic cytokines and models concerning their effects on sleep. Yale J Biol Med 63:157-172.

Lampson LA, Hickey WF (1986) Monoclonal antibody analysis of MHC expression in human brain biopsies: tissue ranging from "histologically normal" to that showing different levels of glial tumor involvement. J Immunol 136:4054-4062.

Lawson LJ, Perry VH, Dri P, Gordon S (1990) Heterogeneity in the distribution and morphology of microglia in the normal adult mouse brain. Neuroscience 39:151-170.

Leverenz J, Petito CK, Morgello S (1988) Neuropathologic change in a patient with narcolepsy. Neurology 38:307.

Lim RKS, Liu C-N, Moffit RL (1960) A stereotaxic atlas of the dog's brain. Springfield, IL: J.L. Books.

Ling EA, Kaur C, Wong WC (1991) Expression of major histocompatibility complex and leukocyte common antigens in amoeboid microglia in postnatal rats. J Anat 177:117-126.

Luber-Narod J, Rogers J (1988) Immune system associated antigens expressed by cells of the human CNS. Neurosci Lett 94:17-22.

Mallat M, Houlgatte R, Brachet P, Prochiantz A (1989) Lipopolysaccharide-stimulated rat brain macrophages release NGF in vitro. Dev Biol 113:309-311.

Matsuki K, Juji T, Honda Y (1988) Immunological features in Japan. In: HLA and narcolepsy (Honda Y, Juji T, eds), pp 58-76. New York: Springer.

Matsuki K, Grumet FC, Lin X, Guilleminault C, Dement WC, Mignot E (1992) HLA DQB1-0602, rather than HLA DRw15(DR2), is the disease susceptibility gene in Black narcoleptics. Lancet 339:1052.

Matsumoto Y, Hara N, Tanaka R, Fujiwara M (1986) Immunohistochemical analysis of the rat CNS during experimental allergic encephalomyelitis, with special reference to Ia-positive cells with dendritic morphology. J Immunol 136:3668-3676.

Mattiace LA, Davies P, Dickson DW (1990) Detection of HLA-DR on microglia in the human brain is a function of both clinical and technical factors. Am J Pathol 136:1101-1114.

McGeer PL, Itagaki S, McGeer EG (1988) Expression of the histocompatibility glycoprotein HLA-DR in neurological disease. Acta Neuropathol (Berl) 76:550-557.

McGeer PL, Kawamata T, Walker DG, Akiyama H, Tooyama I, McGeer EG (1993) Microglia in degenerative neurological disease. Glia 7:84-92.

Mignot E, Nishino S, Sharp L, Arrigoni J, Siegel JM, Reid MS, Edgar DM, Ciaranello RD, Dement WC (1991a) Heterozygosity at the canarc-1 locus can confer susceptibility for narcolepsy: induction of cataplexy in heterozygous asymptomatic dogs after administration of a combination of drugs acting on monoaminergic and cholinergic systems. J Neurosci 13:1057-1064.

Mignot E, Wang C, Rattazzi C, Gaiser C, Lovett M, Guilleminault C, Dement WC, Grumet FC (1991b) Genetic linkage of autosomal recessive canine narcolepsy with an immunoglobulin $\mu$ chain switch-like segment. Proc Natl Acad Sci USA 88:3475-3478. 
Mignot E, Lin X, Arrigoni J, Macaubas C, Olive F, Hallmeyer J, Underhill P, Guilleminault C, Dement WC, Grumet FC (1994) DQB1*0602 and DQA1*0102 are better markers than DR2 for narcolepsy in caucasian and black Americans. Sleep 17:560-567.

Mignot E, Tafti M, Dement WC, Grumet FC (1995) Narcolepsy and immunity. Adv Neuroimmunol 5:23-37.

Murabe Y, Sano Y (1982) Morphological studies on neuroglia. V. Microglial cells in the cerebral cortex of the rat, with special reference to their possible involvement in synaptic function. Cell Tissue Res 223:493-506.

Nakajima K, Tsuzaki N, Nagata K, Takemoto N, Kohsaka S (1992) Production and secretion of plasminogen in cultured rat brain microglia. FEBS Lett 308:179-182.

Nakajima K, Nagata K, Kohsaka S (1994) Plasminogen mediates an interaction between microglia and dopaminergic neurons. Eur Neurol 34:10-16.

Nishino S, Tafti M, Reid MS, Shelton J, Siegel JM, Dement WC, Mignot E (1995) Muscle atonia is triggered by cholinergic stimulation of the basal forebrain: implication for the pathophysiology of canine narcolepsy. J Neuroscience 15:4806-4814.

Parkes JD, Welsh K, Langdon N, Lock CB (1988) Immune factors in narcolepsy in the United Kingdom. In: HLA and narcolepsy (Honda Y, Juji T, eds), pp 158-171. New York: Springer.

Perlmutter LS, Barron E, Chui HC (1990) Morphologic association between microglia and senile plaque amyloid in Alzheimer's disease. Neurosci Lett 119:32-36.

Perry VH, Matyszak MK, Fearn S (1993) Altered antigen expression of microglia in the aged rodent CNS. Glia 7:60-67.

Raivich G, Moreno-Flores MT, Muller JC, Kreutzberg GW (1994) Regulation of microglial proliferation: colony-stimulating factors and their receptors. Neuropathol Appl Neurobiol 20:209-211.

Reid MS, Tafti M, Geary JN, Nishino S, Siegel JM, Dement WC, Mignot E (1994) Cholinergic mechanisms in canine narcolepsy. I. Modulation of cataplexy via local drug administration into the pontine reticular formation. Neuroscience 59:511-522.

Rogers J, Luber-Narod J, Styren SD, Civin WH (1988) Expression of immune system-associated antigens by cells of the human central nervous system: relationship to the pathology of Alzheimer's disease. Neurobiol Aging 9:339-349.
Rubin RL, Hajdukovitch RM, Mitler MM (1988) HLA DR2 association with excessive somnolence in narcolepsy does not generalize to sleep apnea and is not accompanied by systemic autoimmune abnormalities. Clin Immunol Immunopathol 49:149-158.

Sasaki A, Nakazato Y (1992) The identity of cells expressing MHC class II antigens in normal and pathological human brain. Neuropathol Appl Neurobiol 18:13-26.

Sawada M, Kondo N, Suzumura A, Marunouchi T (1989) Production of tumor necrosis factor-alpha by microglia and astrocytes in culture. Brain Res 491:394-397.

Sedgwick JD, Schwender S, Gregersen R, Dorries R, Ter Meulen V (1993) Resident macrophages (ramified microglia) of the adult Brown Norway rat central nervous system are constitutively major histocompatibility complex class II positive. J Exp Med 177:1145-1152.

Sobel RA, Ames MB (1988) Major histocompatibility complex molecule expression in the human central nervous system: immunohistochemical analysis of 40 patients. J Neuropath Exp Neurol 47:19-28.

Sobel RA, Blanchette BW, Bhan AK, Colvin RB (1984) The immunopathology of experimental allergic encephalomyelitis. II. Endothelial cell Ia increases prior to inflammatory cell infiltration. J Immunol 132:2402-2407.

Styren SD, Civin WH, Rogers J (1990) Molecular, cellular, and pathologic characterization of HLA-DR immunoreactivity in normal elderly and Alzheimer's disease brain. Exp Neurol 110:93-104.

Tafti M, Dement WC, Mignot E (1994) CNS expression of HLA Class II molecules in canine narcolepsy. Sleep Res 23:335.

Vass K, Lassmann H (1990) Intrathecal application of interferongamma: progressive appearance of MHC antigens within the nervous system. Am J Pathol 137:3170-3174.

Weinstein DL, Walker DG, Akiyama H, McGeer PL (1990) Herpes simplex virus type I infection of the CNS induces MHC antigen expression on rat microglia. J Neurosci Res 26:55-65.

Wekerle H, Linington C, Lassmann H, Meyermann R (1986) Cellular immune reactivity within the CNS. Trends Neurosci 9:271-277.

Woodroofe MN, Bellamy AS, Feldmann M, Davison AN, Cuzner ML (1986) Immunocytochemical characterization of the immune reaction in the central nervous system in multiple sclerosis: possible role for microglia in lesion growth. J Neurol Sci 74:135-152. 